\title{
Wheat grain drying kinetics in a thin layer
}

\section{Vyacheslav Mykhailyk ${ }^{1}$, Sviatoslav Lementar ${ }^{2}$, Roman Yakobchuk ${ }^{2}$, Yevhen Skrynnyk ${ }^{2}$, Roman Semenko ${ }^{2}$}

\author{
1- Institute of Engineering Thermophysics, National Academy of Sciences of \\ Ukraine, Kyiv, Ukraine \\ 2 - National University of Food Technologies, Kyiv, Ukraine
}

\section{Keywords:}

Grain

Wheat

Drying

Layer

Moisture

\section{Article history:}

Received 20.09.2016

Received in revised form 28.11.2016

Accepted 30.12.2016

Corresponding author:

Roman Yakobchuk

E-mail:

yakroman@ukr.net

DOI: $10.24263 / 2310-$

1008-2016-4-2-13

\section{Abstract}

Introduction. Patterns of wheat grain drying in a layer for justification of the rational modes of grain thermal treatment in drying apparatuses of convective type are investigated.

Materials and methods. Wheat grain was used in the research. To provide grain with field humidity it was artificially humidified. Humidity was determined by exsiccation to bone-dry weight. The research of drying process was conducted on the experimental stand of convective type.

Results and discussions. The analysis of results of the pilot studies of wheat grain convective drying with different humidity showed that increasing of the drying medium temperature from 80 to $100{ }^{\circ} \mathrm{C}$ increases speed and reduces duration of grain drying 2,2-2,3 times, and increase in speed of the drying medium from 1,5 to 2,5 $\mathrm{m} / \mathrm{s}$ causes speed increase and reduction of drying time $20 \%$.

Increase in thickness of the grain layer from 10 to 15 $\mathrm{mm}$ due to increasing of the evaporation area leads to speed increase of drying 1,1-1,2 times depending on the air speed.

At convective drying of the grain indestructible layer of 10 and more $\mathrm{mm}$ high at side blowing by the drying medium to reach identical humidity of grain in the volume of the exemplar for $40 \ldots 60 \mathrm{~min}$. is almost impossible.

Conclusions. It is established that use of the drying agent with the temperature of $100{ }^{\circ} \mathrm{C}$ increases the speed of grain drying 2,2-2,3 times in comparison with the temperature of $80{ }^{\circ} \mathrm{C}$; speed increase of the drying medium from 1,5 to $2,5 \mathrm{~m} / \mathrm{s}$ provides speed increase of grain drying by $\sim 20 \%$. 


\section{- Processes and Equipment of Food Productions}

\section{Introduction}

For development and improvement of small-size mobile grain-dryers of convective type for small farms the problem of technological parameters determination of wheat grain drying in a layer $(10 \ldots 15 \mathrm{~mm})$ aroses $[8,9,10,12]$.

It is possible to dry grain in the different ways $[1,2,7,8,9,13,14]$. The greatest practical use received a convective way with the rapid course of a thermal mass transfer in grain-dryers to the given humidity of grain. A delayed way applies less often, by means of aeration systems, the combined method is rare. In practice almost all wet grain of the reaped crops is dried in the high-speed way. From the total number of the grain-dryers at the enterprises most of all, to $70 \%$, is the share of stationary dryers of the mine type with efficiency more than $10000 \mathrm{~kg} / \mathrm{hr}$. The efficiency of the majority of these dryers does not exceed $40-45 \%$, and specific consumption of power supplies on drying of one tone of grain makes about $12,2 \mathrm{~kg}$ of standard fuel that is by $20-35 \%$ exceeded this index of leading companies analogs such as Shmidt-Zinger, Kembria, Riyela, Metgyuz-k, Pharmfanz, GSI, ME, and so forth $[3,4,5]$.

The use of heat carrier recycling is a perspective way of essential economy of power supplies. Uses of the drying agent with raised, at the expense of recycling, moisture content (from 8 to $30 \mathrm{~g} / \mathrm{kg}$ dry air) at a temperature of $105-120^{\circ} \mathrm{C}$ intensifies heating of grain and practically does not reduce intensity of the process in general for a cycle. At temperature of the drying agent up to $60{ }^{\circ} \mathrm{C}$ (the seed mode) increase in moisture content of the drying agent up to $20 \mathrm{~g} / \mathrm{kg}$ of the dry air causes the decrease of grain drying speed in the layer. It is also proved [5] that at $4-5$ multiple circulation of grain, increase in grain moving speed $4,8-5,1$ times provides the greatest effectiveness, at the same time efficiency of the dryer increases by $6-14 \%$, evaporating ability - by $26-28 \%$, and fuel consumption decrease by $24,4-29,7 \%$.

The main indicators that influence intensity of process and achievement of high rates of grain quality are the temperature of the drying agent, the maximal temperature of grain and duration of drying. For the choice of the optimum drying mode it is necessary that the process of drying would provide high quality of material with minimum drying time. Parameters of drying process can influence differently on grain quality, depending on thermal resistance of its constituents.

As it is specified in [6] with the temperature increase of grain less gluten is washed, especially, when the temperature of the carrier is above $100{ }^{\circ} \mathrm{C}$, and the heating temperature of grain is above $55{ }^{\circ} \mathrm{C}$. The least amount of gluten was washed at the heat carrier temperature when drying at the level of $120^{\circ} \mathrm{C}$ on exposure $60 \mathrm{~min}$. (initial humidity of grain made $20-21 \%$ ). With temperature increase of the heat carrier above $100{ }^{\circ} \mathrm{C}$ and extension of drying term the heating temperature of grain increased more than $50-55^{\circ} \mathrm{C}$ that led to slight decrease of gluten and its strengthening in it. The increase in initial humidity of grain caused more considerable changes. The best index of gluten content was observed at the option of the air-and-sunshine drying, and also when drying at a temperature of $80^{\circ} \mathrm{C}$ of the heat carrier.

Determination of technological parameters of grain drying process in a layer was the purpose of our research, quality indicators of dry grain were not taken into account.

It is apparent that it is also necessary to consider not only the maximal temperature of a product, but also speed of reaching it, that is heating rate, and also duration of endurance of a product at the maximal temperature. Besides, interaction of streams of the heat carrier and grain caused by design features of this dryer [7, 11] is important. 


\section{- Processes and Equipment of Food Productions-}

Therefore, determination of patterns of grain drying process at variable parameters of process for justification of the rational modes of wheat grain thermal treatment in dryers was the purpose of the research.

\section{Materials and methods}

The research object is drying process. For the research of convective grain drying wheat with humidity of $9,1 \%$ was taken. For granting humidity to grain, close to humidity after collecting, it was placed in exsiccators with water for 14 days that provided its with humidification through adsorption to $13,6-18,1 \%$. A part of grain was extra humidified with a spray and placed in an exsiccator with water for 24 hours that allowed to increase humidity to $\sim 24,5-25,8 \%$.

For comparison of curves of grain drying with various humidity the value of absolute moisture content (the relation of water mass to the mass of nonvolatile solids in percentage terms) was given to the dimensionless quantity (moisture content is given).

Grain after humidification was placed in the container $(90 \times 45 \times 20 \mathrm{~mm})$ made of a bolter with holes of $2,5 \times 2,5 \mathrm{~mm}$. In all experiments the container in a drying room was installed with the larger side along a flow of the drying medium. The grain layer height in the container was 10 and $15 \mathrm{~mm}$. Drying was carried out at temperatures of the drying medium of 80,90 and $100^{\circ} \mathrm{C}$ at speed of 1,5 and $2,5 \mathrm{~m} / \mathrm{s}$. Such parameters were chosen because for the use of grain drying in mobile small-size fluidized-bed driers, tape and similar types warming up of a product happens quickly. In such dryers there is an intensive washing of every seed that provides complete warming up of a grain layer.

At a heat carrier speed more than $3 \mathrm{~m} / \mathrm{s}$, there will be an influence on the weighingmachine, that will not allow to provide measurement accuracy of the material mass change while drying. Influence on the weighing-machine will not be carried out at side blowing also.

Researches were conducted at the experimental drying stand which scheme is submitted in Figure 1. The stand consists of the isolated air ducts system with devices for heating (2) and circulation (3) air (drying medium), drying rooms (1), system of automatic control and maintaining of temperature of drying medium $(4,5)$, data collection and processing about the course of the deaquation material process.

The drying room with side blowing has the transparent hatches via which loading of exemplars and overseeing the condition of material in the course of drying are carried out. The drying medium moves by means of a fan blower with the frequency regulation of the impeller turns number that allows to change moving speed of the heat carrier smoothly. The ratio between used and fresh air can be established with the express valves.

The air speed in the drying rooms was controlled by means of a cup anemometer MS13. The temperature of the drying medium and the exemplar during drying time was recorded by means of the thermoelectric converters which are built in the express needle probes. Measurement accuracy of temperature is not worse than $0,1^{\circ} \mathrm{C}$. Calibration of thermoelectric converters was carried out on the boiling water. 


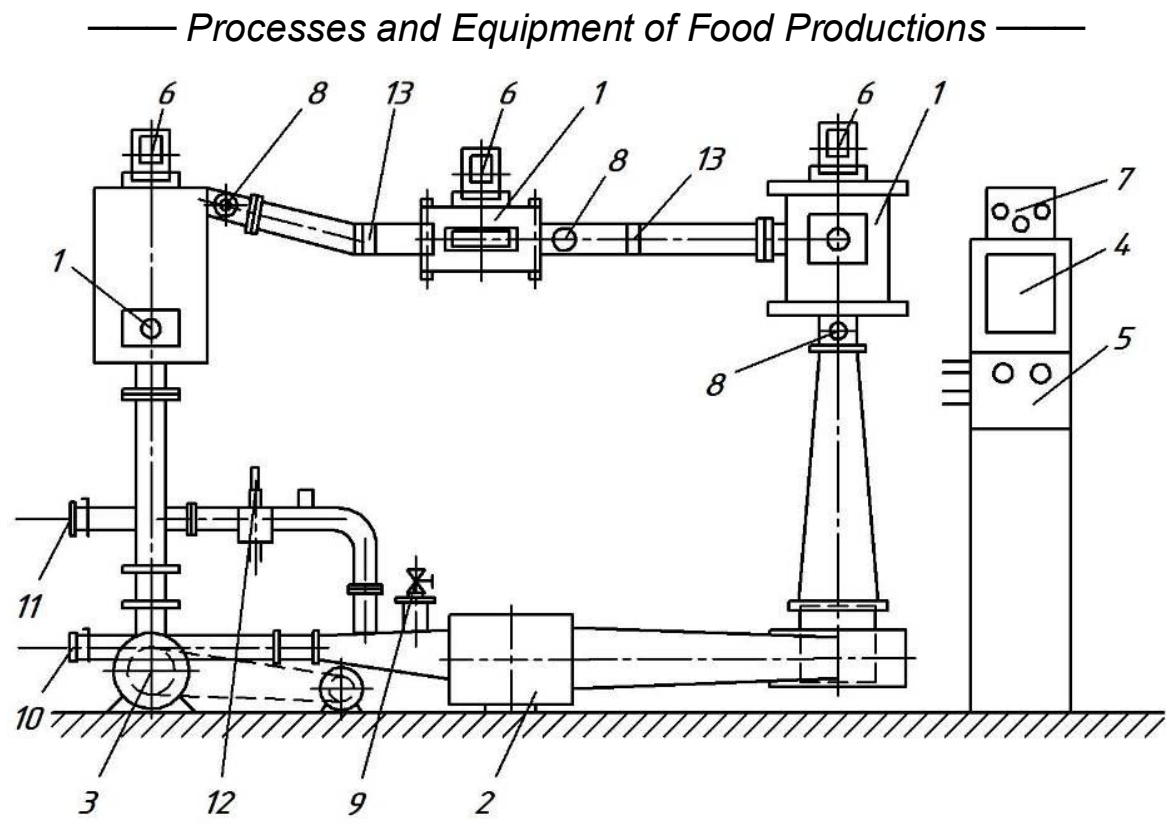

Figure 1. Scheme of the experimental stand of convective drying:

1 -drying rooms; 2 - heater; 3 - fan; 4 - potentiometer; 5 -instrument assembly; 6,7 - automatic regulating system of temperature; 8 - electric resistance pyrometers; $9,10,11$ - branch pipes with slide gates; 12 - hygrodeic, 13 - express lattices

The site of thermal preparation of the drying medium is executed in the form of a rectangular box in which the electric heaters are placed. The system of automatic control consists of the electric resistance pyrometers TSM-50 (8), the PID-regulator with the RS485 OVEN TPM101-KP (4) interface, an optothyristor of the symmetric and electric heaters (2). It allows to maintain air temperature with an accuracy $\pm 0,1^{\circ} \mathrm{C}$ automatically.

The stand is equipped with the automated system of data collection and processing, digital weighing-machine $\mathrm{AD}-500$ and the channels of temperature measurement of the drying medium, a surface of an exemplar and its central part. By means of the computer program information on the drying process course was collected, all necessary calculations and graphic constructions were carried out.

After putting the stand in operating mode, on the scale of the weighing-machine in the drying room a container with an exemplar of grain weighing $30 \ldots 60 \mathrm{~g}$ was installed where probes with temperature sensing devices of the surface (on depth of 2-3 $\mathrm{mm}$ ) and the central part were placed and computer system of data collection and processing which continuously recorded temperature of the drying medium, change of the exemplar mass and its temperature in the drying course was turned on. Drying was carried out within 160 minutes.

For determination of mass nonvolatile solids in the exemplars after completion of drying in the stand grain was transferred to the metal weighing bottles and placed in a drying chamber where finally dried at the temperature of $104-105{ }^{\circ} \mathrm{C}$. The course of deaquation was controlled by weighing of the exemplars on the weighing-machine WA-33 (a weighing error $\pm 0,6 \mathrm{mg}$ ). Process of drying was considered complete when the mass of the exemplar became invariable. 
Using the mass of nonvolatile solids of the exemplar flowing moisture content of material $W$ in a drying time was defined and curves of drying of $W=f(\tau)$ and speeds of drying of $d W / d \tau=f(W)$ were counted and built.

\section{Results and discussions}

In Figure 2 the change curves of moisture content, surface temperatures and the central part of the exemplar of a grain layer of $10 \mathrm{~mm}$ high with initial humidity of $24,86 \%$ when drying at the drying medium temperature of $100{ }^{\circ} \mathrm{C}$ and the speed of $2,5 \mathrm{~m} / \mathrm{s}$ are presented.

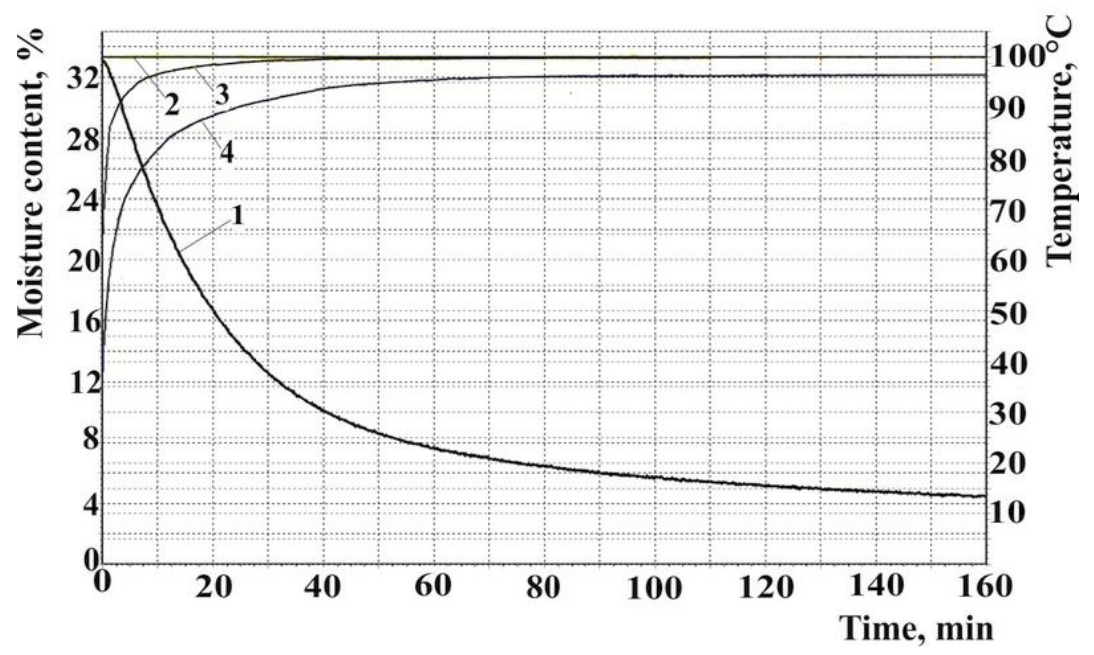

Figure 2. Change of moisture content and temperature of the exemplar of wheat grain

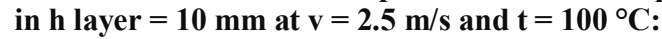

1 - moisture content; 2 - temperature of the drying medium; 3 - surface temperature of the exemplar; 4 - temperature in the center of the exemplar

From the data submitted in the drawing it is visible that temperature at the surface layer of the exemplar becomes equal to the drying medium temperature for $40 \mathrm{~min}$. that corresponds to an average moisture content of the exemplar in $10 \%$. Now the difference of temperatures in the central part of the exemplar and the drying medium makes $6{ }^{\circ} \mathrm{C}$ and until the end of the experiment decreases only about $3,5{ }^{\circ} \mathrm{C}$ that testifies to an incompleteness of deaquation and existence of a moisture content gradient in the basis volume of the exemplar. That is at convective drying of the fixed grain layer more than 10 $\mathrm{mm}$ high identical humidity of grain in the volume of the exemplar for a reasonable time period cannot be reached.

The received kinetic curves of grain dryings $(\mathrm{Wp}=14-18 \%)$ in $\mathrm{h}$ layer $=10 \mathrm{~mm}$ at $\mathrm{v}$ $=2,5 \mathrm{~m} / \mathrm{s}$ and temperatures of drying medium 80,90 and $100{ }^{\circ} \mathrm{C}$ demonstrate the increase in drying speed (Figure 3) and decrease of deaquation time (Figure 4) with increase of the temperature. 


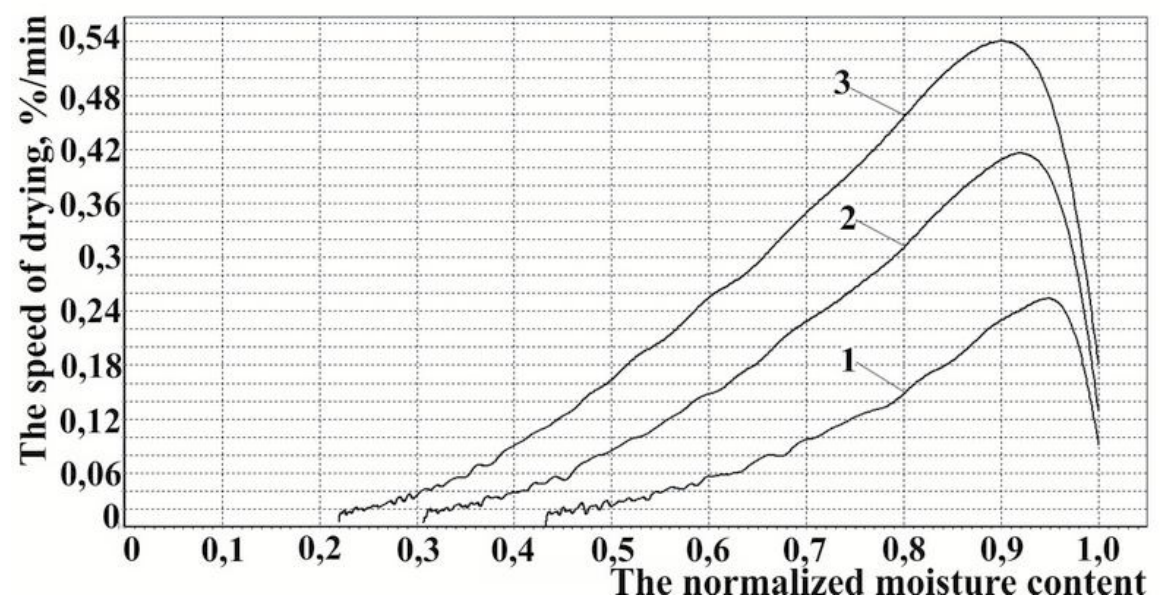

Figure 3. Curves of speeds of wheat grain drying in $h$ layer $=10 \mathbf{m m}$ at $\mathbf{v}=\mathbf{2 , 5} \mathbf{~ m} / \mathbf{s}$ at $\mathbf{t},{ }^{\circ} \mathbf{C}: 1-80 ; 2-90 ; 3-100$

So grain gains moisture content in $10 \%$ (the horizontal line in Figure 4) for 34,3 min. at the temperature of the drying medium of $100^{\circ} \mathrm{C}$, for $50,7 \mathrm{~min}$. - at $90{ }^{\circ} \mathrm{C}$ and for $110 \mathrm{~min}$. - at $80{ }^{\circ} \mathrm{C}$. That is temperature increase of the drying medium from 80 to $100{ }^{\circ} \mathrm{C}$ leads to reduction of drying time of grain to average humidity 9,9\% 3,2 times.

Reduction of drying time is the consequence of drying speed increase which maximum size at change of the drying medium temperature from 80 to $100{ }^{\circ} \mathrm{C}$ increases from 0,26 to $0,54 \% / \mathrm{min}$. (Figure 3).

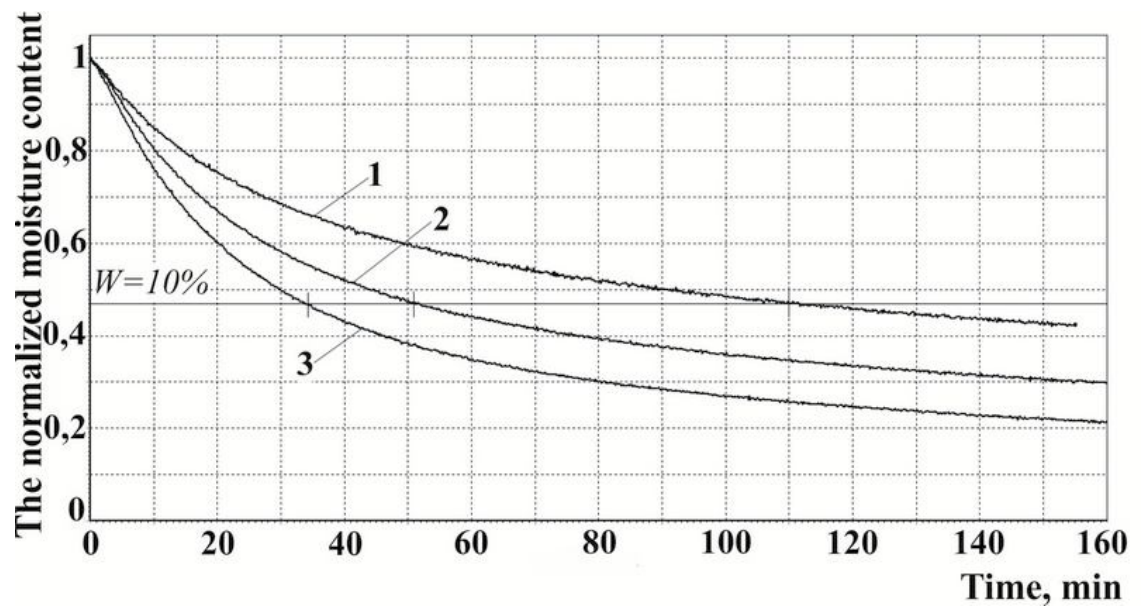

Figure 4. Curves of wheat grain drying in $h$ layer $=10 \mathrm{~mm}$ at $\mathrm{v}=\mathbf{2 . 5} \mathrm{m} / \mathrm{s}$ for $\mathbf{t},{ }^{\circ} \mathbf{C}: 1-80 ; 2-90 ; 3-100$ 


\section{- Processes and Equipment of Food Productions -}

Increase in the drying medium speed from 1,5 to $2,5 \mathrm{~m} / \mathrm{s}$ leads to the speed increase (Figure 6) and reduction of the drying time (Figure 5). So at the temperature of $100^{\circ} \mathrm{C}$ in a layer $10 \mathrm{~mm}$ high the grain drying time with moisture content of $10 \%$ decreases from 42,5 to $34,3 \mathrm{~min}$., that is by $19,3 \%$.

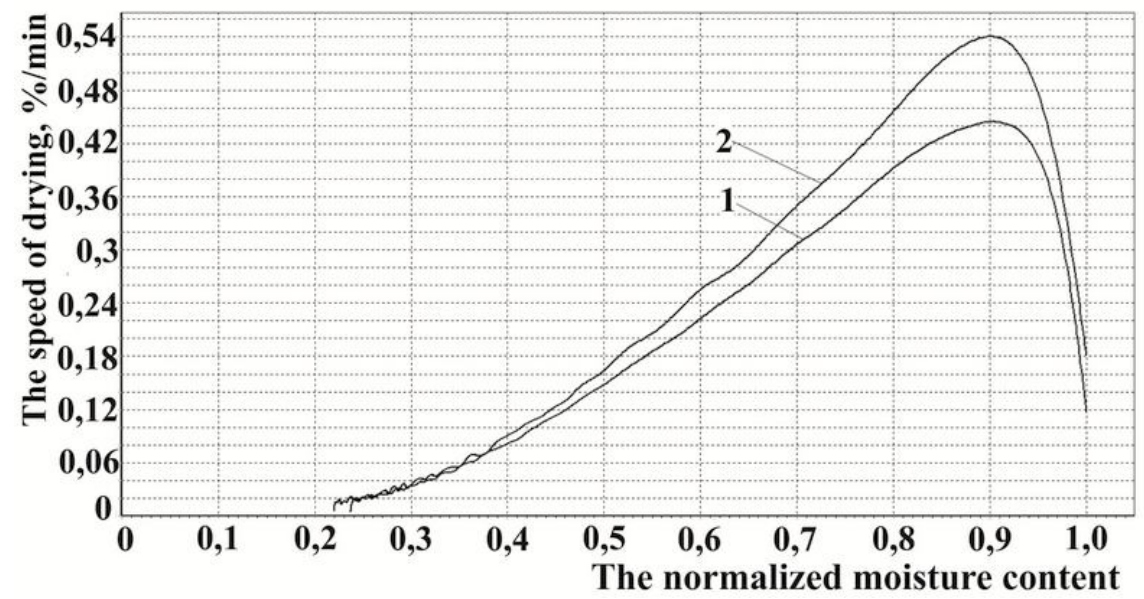

Figure 5. Curves of wheat grain drying in $h$ layer $=10 \mathrm{~mm}$ for $\mathrm{t}=100{ }^{\circ} \mathrm{C}$ at $\mathrm{v}=1,5(1)$ and $\mathrm{v}=2,5 \mathrm{~m} / \mathrm{s}(2)$

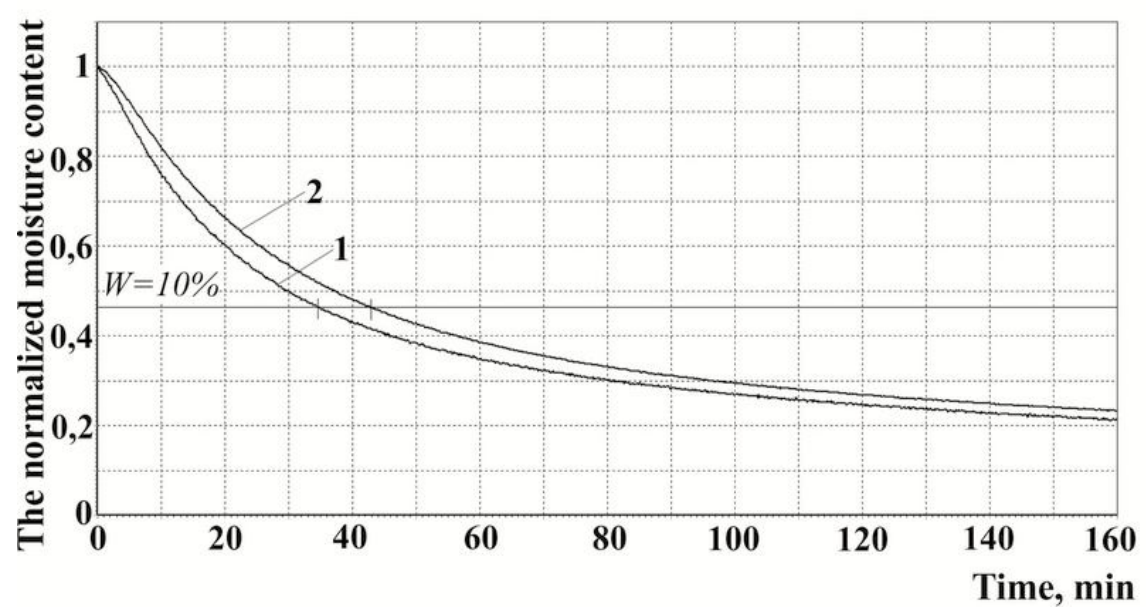

Figure 6. Curves of wheat grain drying in $h$ layer $=10 \mathrm{~mm}$ at $\mathrm{t}=100{ }^{\circ} \mathrm{C}$ at $\mathrm{v}=2,5(1)$ and $\mathrm{v}=1,5 \mathrm{~m} / \mathrm{s}(2)$

The research of kinetics of grain drying in a layer of 10 and $15 \mathrm{~mm}$ showed that in this case the size of the external surface of the exemplar and the change of air filtration in the exemplar under pressure of the drying medium stream begin to play a role. With a height of a grain layer in $10 \mathrm{~mm}$ the conditional (without the surface of grains) external surface of the exemplar makes $10800 \mathrm{~mm}^{2}$, with a height of $15 \mathrm{~mm}-12150 \mathrm{~mm}^{2}$. From Figure 7 it is visible that the speed of deaquation is more for the exemplar with a larger external surface. 


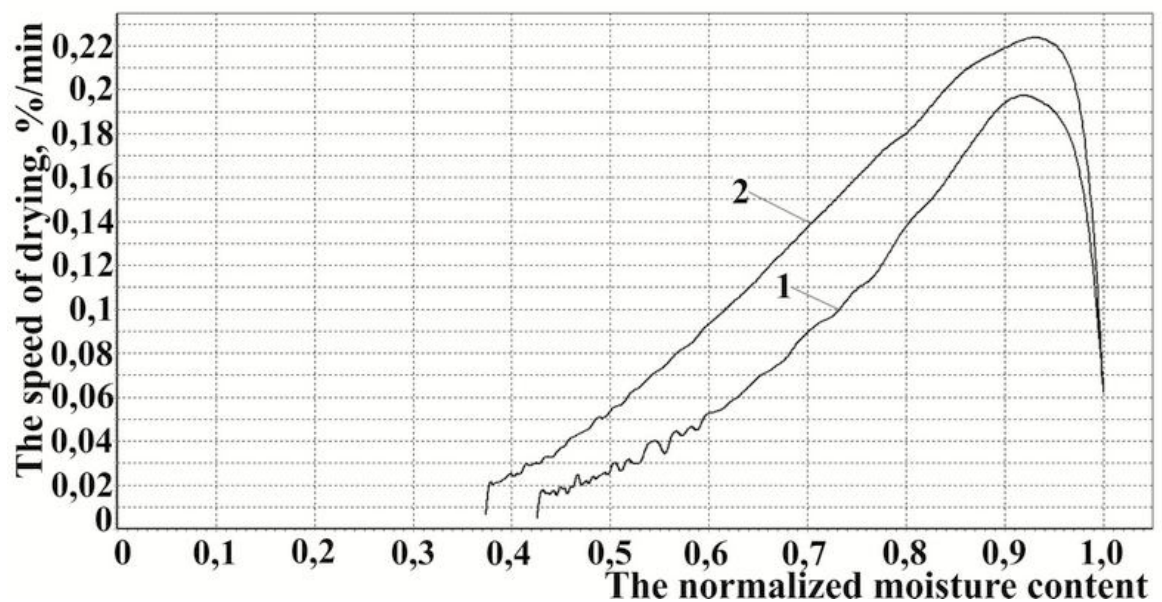

Figure 7. Curves of speed of wheat grain drying in $h$ layer $=10(1)$ and $h=15 \mathrm{~mm}(2)$ at $v=1,5 \mathrm{~m} / \mathrm{s}$ and $t=80^{\circ} \mathrm{C}$

Various mass of exemplars and size of an external surface are reflected through the speed change in the drying curves (Figure 8). During the initial phase of drying when a part of warmth is spent for material heating the drying curves go nearby, but higher speed of grain drying in a layer of $15 \mathrm{~mm}$ high leads to the fact that the curves at $33 \mathrm{~min}$. are crossed. And the grain exemplar in a layer of $15 \mathrm{~mm}$ high reaches moisture content of $10 \%$ earlier (for 42,5 min.), Than in a layer $10 \mathrm{~mm}$ high (for 45,2 min.).

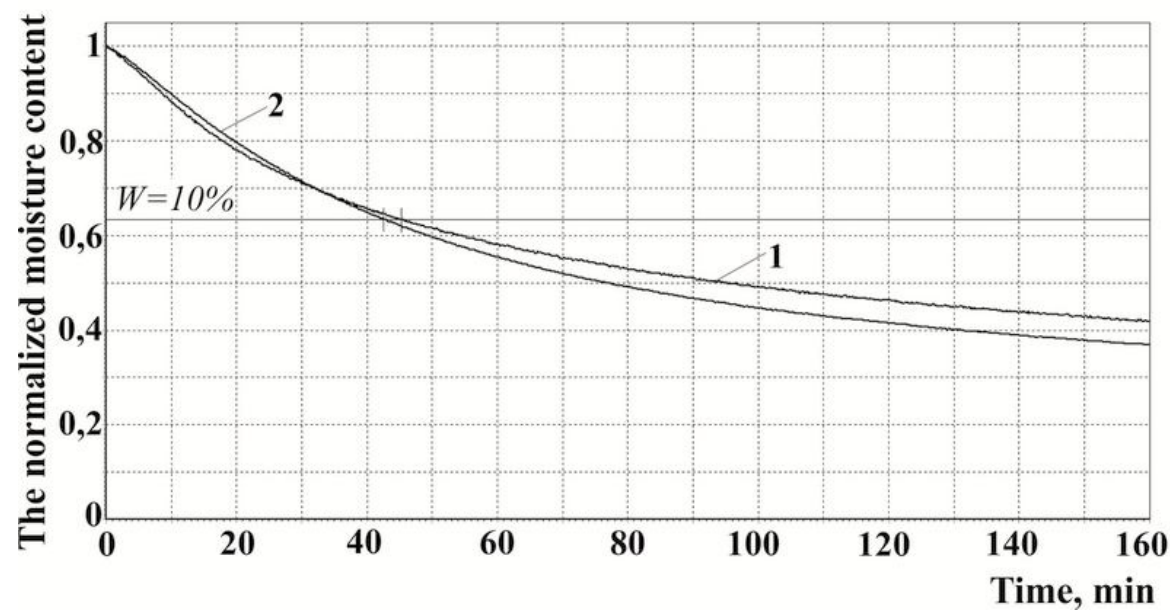

Figure 8. Curves of wheat grain drying in $h$ layer $=10(1)$ and $h=15 \mathrm{~mm}(2)$ at $v=1,5 \mathrm{~m} / \mathrm{s}$ and $t=80^{\circ} \mathrm{C}$

Drying of grain with the initial humidity that significantly differs in the size are presented in Figure $\mathrm{s} 9$ and 10. 


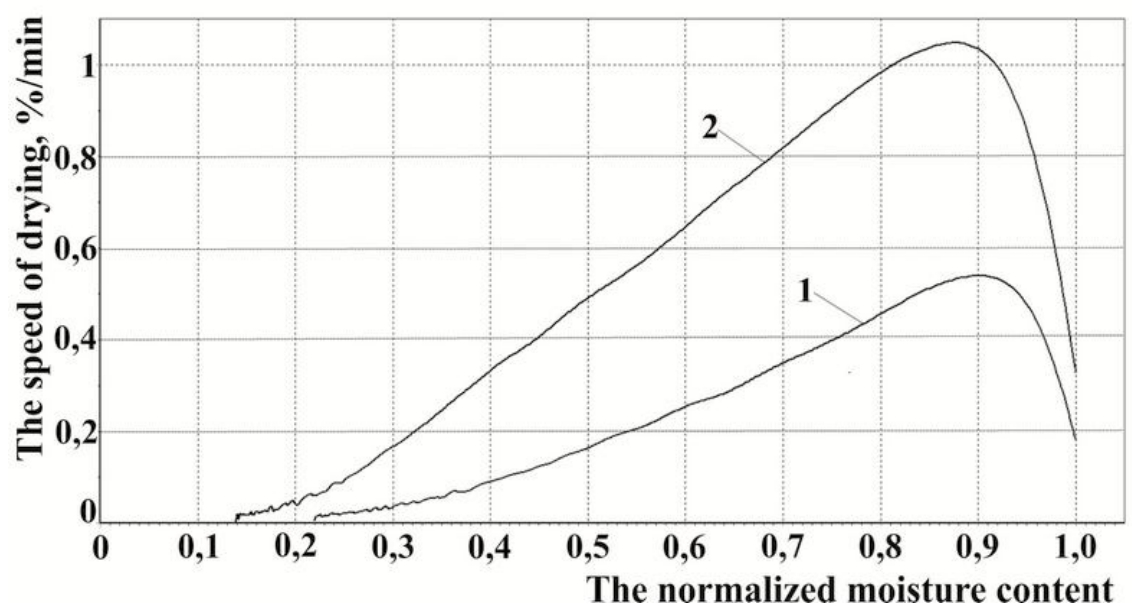

Figure 9. Curve speeds of drying of grain of wheat with initial humidity of 17,8 (1) and 24,9\%

(2) in h layer $=10 \mathrm{~mm}$ at $\mathrm{v}=1,5 \mathrm{~m} / \mathrm{s}$ and $\mathrm{t}=100^{\circ} \mathrm{C}$

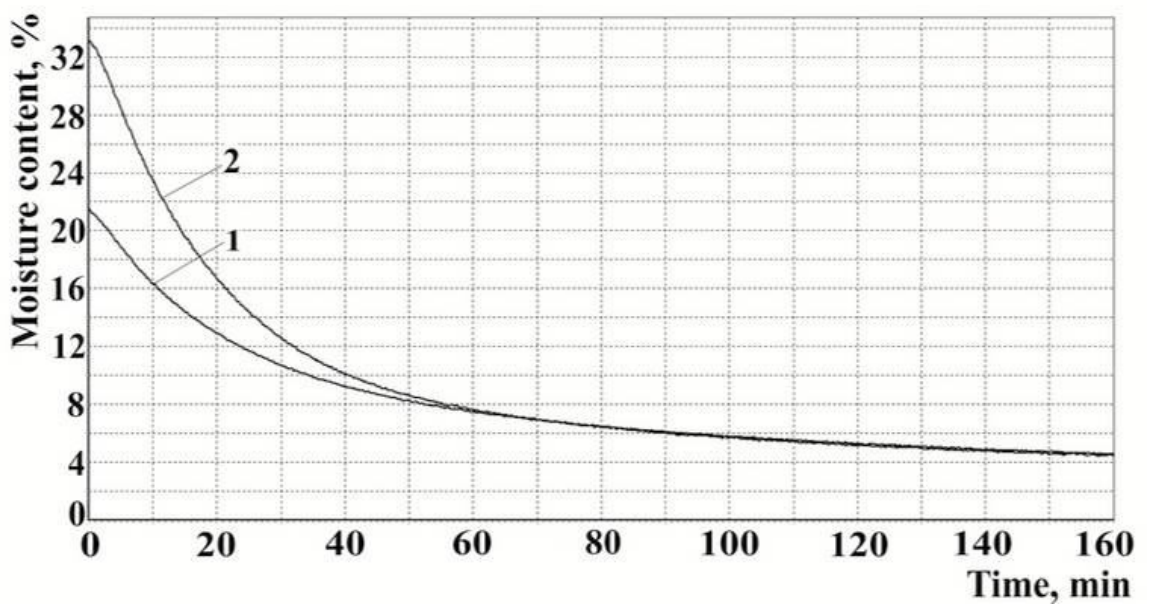

Figure 10. Curves of wheat grain drying with initial humidity of 17,8 (1) and $24,9 \%$ (2) in $\mathrm{h}$ layer $=10 \mathrm{~mm}$ at $\mathrm{v}=1,5 \mathrm{~m} / \mathrm{s}$ and $\mathrm{t}=100^{\circ} \mathrm{C}$

We can see that the speed of drying of the exemplar with the initial humidity of $24,9 \%$ in a layer of $10 \mathrm{~mm}$ high at speed of the drying medium of $2,5 \mathrm{~m} / \mathrm{s}$ and temperature of 100 ${ }^{\circ} \mathrm{C}$ is much higher that for the exemplar with the initial humidity of $17,8 \%$. Despite rather high difference in speeds of drying, deaquation of the exemplar with lower initial humidity goes so that it reaches $10 \%$ of moisture content earlier (for $34,3 \mathrm{~min}$.), than the exemplar with higher humidity (for 40,4 min.). However, their moisture content is equalized $(7,4 \%)$ for $65 \mathrm{~min}$. of drying. 


\section{- Processes and Equipment of Food Productions}

The received results of the pilot studies of convective wheat grain drying allowed to establish dependences of duration and speed of drying on parameters of the heat carrier and characteristics of starting material (wheat grain). These results can be used for development new and improvement of the existing mobile small-size drying equipment for grain crops drying.

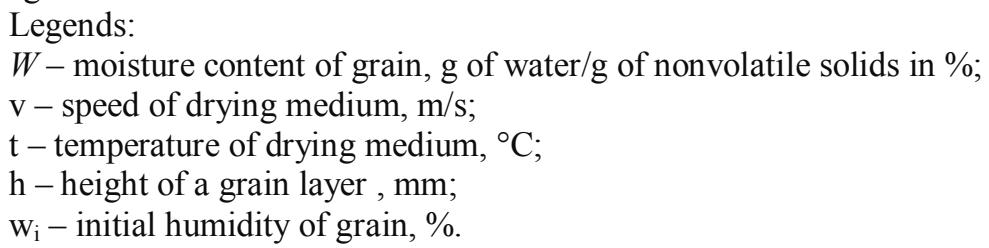

\section{Conclusions}

The pilot studies of convective wheat grain drying in a layer showed positive influence on the drying kinetics temperature increase and speeds of the drying medium:

- temperature increase of the drying medium from 80 to $100{ }^{\circ} \mathrm{C}$ increases speed and reduces duration of grain drying 2,2-2,3 times;

- increase in speed of the drying medium from 1,5 to $2,5 \mathrm{~m} / \mathrm{s}$ causes speed increase and reduction of the drying time $\sim 20 \%$

Increase in thickness of the grain layer from 10 to $15 \mathrm{~mm}$ due to increase in the evaporation area leads to increase in speed of drying 1,1 - 1,2 times depending on the air speed.

Due to a moisture content gradient in the volume of the exemplar in the fixed state arising at convective wheat grain drying of 10 and more mm high with a side blowing by the drying medium to reach identical humidity of grain in the volume of the exemplar for $40 . .60 \mathrm{~min}$. is almost impossible.

Influence of temperature (in limits of $80-100^{\circ} \mathrm{C}$ ) and speeds of the drying medium (within $1,5-2,5 \mathrm{~m} / \mathrm{s}$ ) on the speed of the grain side layer drying of 10 and $15 \mathrm{~mm}$ thick was defined for the first time.

\section{References}

1. Malin N.I., Veselovskaja T.I. (2001), Teoreticheskie osnovy tehnologicheskih processov [Theoretical bases of technological processes], Hleboprodinform, Moscow.

2. Maier D.E., Bakker-Arkema F.W. (2002), Grain drying systems. In: Proceedings of the 2002 Facility Design Conference of the Grain Elevator \& Processing Society, St. Charles, IL, July 28-31, 2002, pp. 1-53.

3. Haponyuk I.I (2009), Udoskonalennya tekhnolohiyi sushinnya zerna [Improving the technology of grain drying], Polihraf, Odesa.

4. Lisets'kyy V.O., Kotov B.I. (2001), Pidvyshchennya enerhetychnoyi efektyvnosti zernosusharok [Improving the energy efficiency of dryers], Agricultural Machinery, 9, pp. 104-109.

5. Kotov B.I., Lisets'kyy V.O. (2001), Analiz vplyvu rezhymu sushinnya zerna na enerhetychni kharakterystyky zernosusharok [Analysis of the influence of grain drying mode on the energy characteristics of grain dryers], Bulletin of Kharkiv State Technical University of Agriculture, 8, pp. 166-170. 


\section{- Processes and Equipment of Food Productions-}

6. Kovalenko O.A., Kosovska N.V. (2012), Vplyv rezhymiv sushinnya zerna pshenytsi ozymoyi na pokaznyky yoho prodovol'chykh i nasinnyevykh yakostey [Influence of drying modes of winter wheat in the performance of its food and seed quality], Proceedings of Petro Mohyla Black Sea State University complex "Kyiv-Mohyla Academy",179(no. 167), pp. 68-72.

7. Scaar H., Franke G., Weigler F., Delele M.A., Tsotsas E., Mellmann J. (2016), Experimental and numerical study of the airflow distribution during mixed-flow grain drying, Drying Technology 34(5), pp. 595-607, http://www.doi.org/10.1080/07373937.2015.1064946

8. Yakobchuk R. (2014), The influence of design parameters of rotary dryer on sunflower seeds drying, Ukrainian Food Journal 3(3), pp. 437-445.

9. Pokhozhaiev O., Yakobchuk R. (2014), Improvement of drying process of beer pellet in the fluidized bed apparatus, Ukrainian Journal of Food Science 2(2), pp. 296-304.

10. Debabandya Mohapatra, P. Srinivasa Rao (2005), A thin layer drying model of parboiled wheat, Journal of Food Engineering, 66(4), pp. 513-518, http://dx.doi.org/10.1016/j.jfoodeng.2004.04.023

11. Fabian Weigler, Jochen Mellmann (2014), Investigation of grain mass flow in a mixed flow dryer, Particuology 12, pp. 33-39, http://dx.doi.org/10.1016/j.partic.2013.04.004

12. Sivakumar R., Saravanan R., Elaya Perumal A., Iniyan S. (2016), Fluidized bed drying of some agro products - A review, Renewable and Sustainable Energy Reviews 61, pp. 280-301, http://dx.doi.org/10.1016/j.rser.2016.04.014

13. Al-Mahasneh M.A., Rababah T.M., Bani-Amer M.M., Al-Omari N.M., Mahasneh M.K. (2013), Fuzzy and conventional modeling of open sun drying kinetics for roasted green wheat, International Journal of Food Properties, 16(1), pp. 70-80, http://dx.doi.org/10.1080/10942912.2010.528108

14. Haydar Kucuk, Adnan Midilli, Aydin Kilic, Ibrahim Dincer (2014), A review on thin-layer drying-curve equations, Drying Technology An International Journal, 32(7), pp. 757-773, http://dx.doi.org/10.1080/07373937.2013.873047 